\title{
Screening equilibria in experimental markets
}

\author{
Lisa L. Posey $\cdot$ Abdullah Yavas
}

Received: 5 June 2006/Revised: 28 April 2007/Published online: 9 October 2007

(C) The Geneva Association 2007

\begin{abstract}
We conduct an experimental test of a screening model of an insurance market with asymmetric information. We first conduct three sessions in which the proportion of high risk buyers is such that a separating equilibrium should exist. We then conduct three more sessions in which the only change we make is decreasing the proportion of high risks such that the equilibrium is now a pooling equilibrium. In both treatments, the observed behavior converges to the equilibrium prediction.
\end{abstract}

Keywords Screening equilibrium $\cdot$ Experiments

\section{JEL Classifications C92 $\cdot$ D81}

\section{Introduction}

In their classic paper, Rothschild and Stiglitz (1976) analyze a competitive insurance market under asymmetric information with two policyholder risk types, or probabilities of having a fixed loss amount. Their model is a screening model where uninformed insurers move first offering a menu of contracts, defined as pricequantity pairs, to informed policyholders. They conclude that the only Nash equilibrium in this setting is a separating equilibrium, and that this equilibrium exists only if the proportion of high risk policyholders is sufficiently large. In this equilibrium the price-quantity pairs allow insurers to deduce policyholder risk types by their contract choices.

L. L. Posey $(\bowtie) \cdot$ A. Yavas

Penn State University, Business Building, University Park, PA 16802, USA

e-mail: 1lp3@psu.edu
A. Yavas
e-mail: ayavas@psu.edu 
Rothschild and Stiglitz (1976) has inspired a tremendous amount of additional research. This subsequent research is noteworthy in terms of the wide variety of fields to which the theoretical model has been applied. ${ }^{1}$ A less substantial body of empirical work has attempted to test the predictions of the Rothschild-Stiglitz (R-S) screening model. ${ }^{2}$ A major impediment to this empirical work is the inherent unobservability of customer types. This problem can be overcome with the experimental approach which allows us to control for the risk types of the customers.

In this paper, we conduct an experimental test of a parameterized version of the R$\mathrm{S}$ screening model with asymmetric information. Our focus is on the strategic behavior of firms that offer menus of contracts to screen customers by risk type. Although a number of experiments have tested separating versus pooling equilibria in signaling models (e.g., Miller and Plott 1985; Cadsby et al. 1990), to our knowledge there are only three other experimental tests of screening models: Shapira and Venezia (1999), Berg et al. (1987, Unpublished) and Kübler et al. (2005). In a signaling model, the informed party makes the first move, while in a screening model the uninformed party makes the first move. This difference in sequencing can have an important impact on the resulting equilibria. As Stiglitz and Weiss (1983) point out, when the informed parties move first, multiple equilibria may exist, while in the case where the uninformed move first, multiple equilibria cannot exist.

Shapira and Venezia (1999) frame their experiment in an insurance setting. They look at the pricing strategies of insurance sellers facing simulated buyers with private information about their risk type (high or low risk). Two insurance contracts are available, one with and the other without a deductible. They are unable to find support for the hypothesis that sellers will screen buyers with respect to their risk types. In our experiment, we find strong support for a separating equilibrium where sellers screen buyers with respect to risk type. A major difference between their experiment and our experiment is that their experiment did not allow the subjects to learn because each session involved only one round. ${ }^{3}$ In contrast, the subjects in our experiment played the same game for 30 rounds. It is also somewhat difficult to assess the significance of their findings because some of their sessions did not link the compensation of subjects to their decisions.

Berg et al. (1987, Unpublished) focus on discriminating between the Rothschild and Stiglitz (1976), Wilson (1977) and Riley (1979) screening models. ${ }^{4}$ Their experiment involves two treatments. In their first treatment, the proportion of high risks is sufficiently high so that all three models predict the same separating

\footnotetext{
1 See, for example, Stiglitz and Weiss (1981), Brueckner (1992) and Rubinfeld and Schotchmer (1993). Examples of extensions of the model include Crocker and Snow (1985, 1986), Hoy (1982), Doherty and Posey (1998) and Cooper and Hayes (1987).

2 Several studies have tested for the existence of adverse selection in insurance markets (in auto insurance, Dahbly 1983; D’Arcy and Doherty, 1990 and Puelz and Snow, 1994; in medical and life insurance, Browne 1992 and Browne and Doerpinghaus 1994). The results of these tests have been mixed.

3 Although some sessions included up to four rounds, additional information was provided to the subjects between each round in these sessions, so the rounds differed from each other.

4 Wilson (1977) and Riley (1979) develop alternative equilibrium concepts to be applied to the same type of problem studied by Rothschild and Stiglitz. The main distinction between the Nash equilibrium concept and those of Wilson and Riley is that the latter two require some form of sustainable profitability of contracts as a condition for breaking a potential equilibrium.
} 
equilibrium. In their second treatment, the proportion of high risks is low enough such that the three models differ in their predictions. Berg et al. (1987, Unpublished) were unable to find support for any of the three models in this second treatment. We are not attempting to distinguish between these three models, but are focusing on the Nash equilibrium concept instead. Another difference is that, to make the procedure more tractable for the subjects in the role of buyers, Berg et al. (1987, Unpublished) limited the choice of sellers to four contracts (pricequantity pairs). This very strong restriction is necessary because of the complexity of the model. In our experiment, we allow sellers to offer one or both of two quantities of insurance, full coverage or partial coverage, and effectively allow them to choose any price above zero up in increments of one decimal point. To make the procedure more tractable for participants in our experiment, the buying decisions are made by a computer and we focus on the behavior of sellers and whether they indeed attempt to screen buyers by risk type in an environment where sellers have many contract options.

The experimental paper by Kübler et al. (2005) compares two versions of Spence's education game, signaling and screening, to test how outcomes are affected by the order of moves. They find significantly more separating behavior with signaling than with screening. They also test the impact of competition and find that increasing the number of employers leads to higher wages in the signaling game but not in the screening game.

In this paper, we develop a parameterized example of the R-S screening model and utilize these parameters to design our experimental sessions. The key parameter in our experiment is the proportion of high risks. In our experimental setting, the unique Nash equilibrium outcome is a separating equilibrium when the proportion of high risks is sufficiently high. When the proportion of high risks is too low, a separating equilibrium cannot be sustained, and due to restrictions on the number of coverage options that firms can offer in our experimental setting, the unique Nash equilibrium is a pooling equilibrium. ${ }^{5}$ Our results provide striking evidence for screening behavior by sellers. We first conduct three sessions of our experiment in which the proportion of high risks is such that a separating equilibrium should exist. Not only are sellers in our experiment able to screen high risk and low risk buyers, but they also price both full coverage and partial coverage contracts at their equilibrium levels. We then conduct three additional sessions where we decrease the proportion of high risks sufficiently to generate a predicted pooling equilibrium. Once again, the observed behavior converges to the equilibrium prediction, although at a slower rate than it did in the three separating equilibrium sessions.

The next section presents both a theoretical and parameterized version of a screening model of an insurance market. The parameters are utilized in our experiment. Section 3 describes the design of the experiment. Experimental procedures are provided in Sect. 4. Section 5 reports the results of the experiment. Section 6 offers concluding remarks.

\footnotetext{
5 Without these quantity restrictions, no equilibrium would exist, as is the case with R-S.
} 


\section{Screening model of an insurance market}

Rothschild and Stiglitz (1976) develop a model of a competitive insurance market with asymmetric information. All potential policyholders are endowed with initial wealth $W$ and each faces two possible states of nature, the loss state, with a reduction in wealth to $W-X$, and the no loss state where wealth remains at $W$. They assume two types of potential policyholders (or customers), high risk and low risk. The probability of the loss state is $p_{L}$ for low risks and $p_{H}$ for high risks, with $p_{L}<p_{H}$. The corresponding probability of the no loss state for type $i$ is $1-$ $p_{i}, i=L, H$. The proportion of high risk individuals in the market is $\lambda$ and $1-\lambda$ is the proportion of low risk individuals. All parties know $W, \lambda, p_{L}, p_{H}, X$ and the utility function of potential policyholders $U(\mathrm{~A})$ defined over wealth. But each customer's probability of a loss is private information to that customer and the insurers know only the proportion of high and low risks, not which customers are which risk type. Potential policyholders are expected utility maximizers and it is assumed that $U^{\prime}>0$ and $U^{\prime \prime}<0$.

The insurance premium paid in all states of nature is $\alpha$ and $I$ is the payment made to the insured in the loss state. Therefore, an insurance contract can be defined as a pair $(\alpha, I)$. A Nash equilibrium is defined as a set of contracts such that, when each customer chooses a contract to maximize his or her expected utility, no equilibrium contract yields negative profits and no insurer has an incentive to offer contracts outside the equilibrium set. This equilibrium is a screening equilibrium which induces individuals of each risk type to buy the policy or contract designed for them and, consequently, to reveal their information. Let $\left(\alpha_{i}, I_{i}\right)$ represent a contract intended for a type $i$ individual, $i=L, H$. Rothschild and Stiglitz (1976) show that for sufficiently large $\lambda$, there exists a separating equilibrium which is characterized by the following:

(a) the low and high risk policies each yield non-negative profits,

$$
\begin{gathered}
\alpha_{H}-p_{H} I_{H} \geq 0 \\
\text { and } \quad \alpha_{L}-p_{L} I_{L} \geq 0,
\end{gathered}
$$

(b) high risks have no incentive to choose the low risk policy,

$$
\begin{aligned}
& \left(1-p_{H}\right) U\left(W-\alpha_{H}\right)+p_{H} U\left(W-X-\alpha_{H}+I_{H}\right) \\
& -\left(1-p_{H}\right) U\left(W-\alpha_{L}\right)-p_{H} U\left(W-X-\alpha_{L}+I_{L}\right) \geq 0,
\end{aligned}
$$

(c) low risks receive the highest expected utility possible given that (1)-(3) are satisfied. Therefore, the separating Nash equilibrium can be derived by maximizing the expected utility of low risks

$$
\left(1-p_{L}\right) U\left(W-\alpha_{L}\right)+p_{L} U\left(W-X-\alpha_{L}+I_{L}\right)
$$

subject to conditions (1)-(3). 


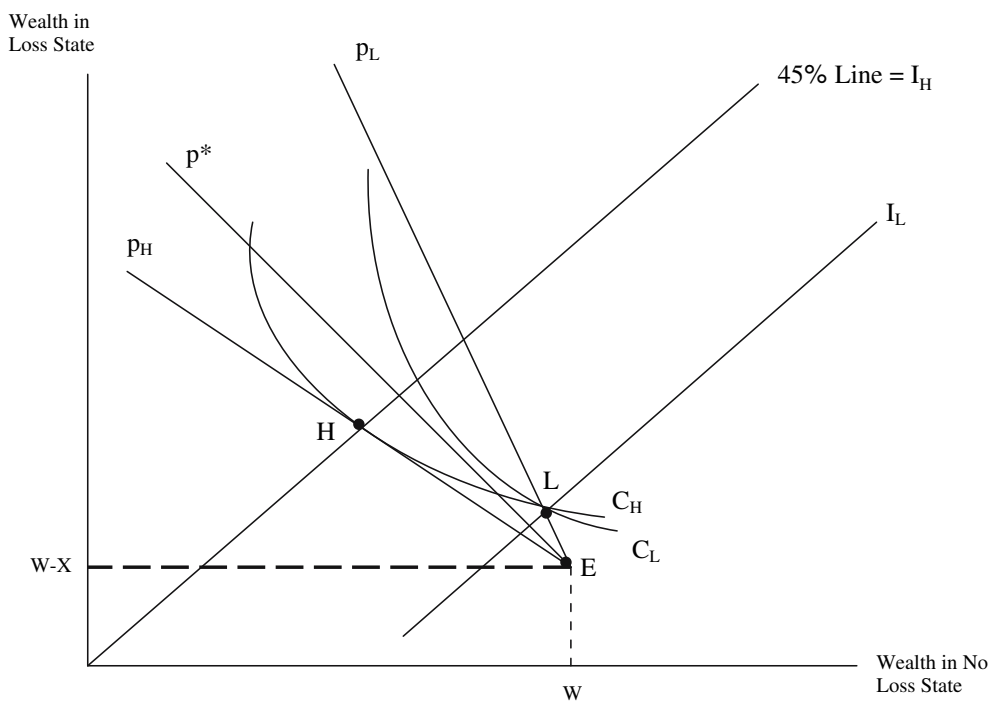

Fig. 1 Proportion of high risks large enough for a separating equilibrium to exist

If there is a sufficiently low percentage of high risks, the above described separating equilibrium can be broken by a pooling contract, since the pooling premium would be low enough to attract the low risks away from their separating contract.

Figure 1 depicts the separating Nash equilibrium outcome for the R-S model. E is the initial endowment; wealth in the loss state is shifted from $W$ to $W-X$. The line labeled $p_{H}$ is the zero-profit line for high risk policies and has slope $-\left(1-p_{H}\right) / p_{H}$; the line labeled $p_{L}$ is the zero-profit line for low risk policies having slope $-\left(1-p_{L}\right) / p_{L}$. The pooled price line, labeled $p^{*}$, gives the zero-profit policies for an average risk having a probability of loss of $p^{*}=(1-\lambda) p_{L}+\lambda p_{H}$. The Nash equilibrium contract for high risks is the full insurance contract labeled $H$. The equilibrium contract for low risks, $L$, gives high risks the same level of expected utility as $H$, as can be seen by the fact that the indifference curve $C_{H}$ passes through both $H$ and $L{ }^{6}$

Note that the indifference curve for risk type $i$ is tangent to the zero profit line $p_{i}$ at the full insurance line. Since $p_{H}>p_{L}$, the slope of a high risk indifference curve through any point is flatter than the slope of a low risk indifference curve through the same point. The separating Nash equilibrium is unique and exists if and only if the indifference curve for a low risk through $L, C_{L}$, does not cross the pooled price line $p^{*}$ as is the case in Fig. 1. Now consider Fig. 2 where the proportion of high risks is sufficiently low such that the pooled price line $p^{*}$ crosses $C_{L}$. Then an insurer can offer a contract in the region between $C_{L}$ and the pooled price line and that contract will attract both risk types away from the separating contracts and earn positive profits (because the contract is to the southwest of the pooled price line). In

\footnotetext{
6 The line $I_{L}$, which appears in both Figs. 1 and 2, pertains to our experimental version of the model and will be discussed below.
} 


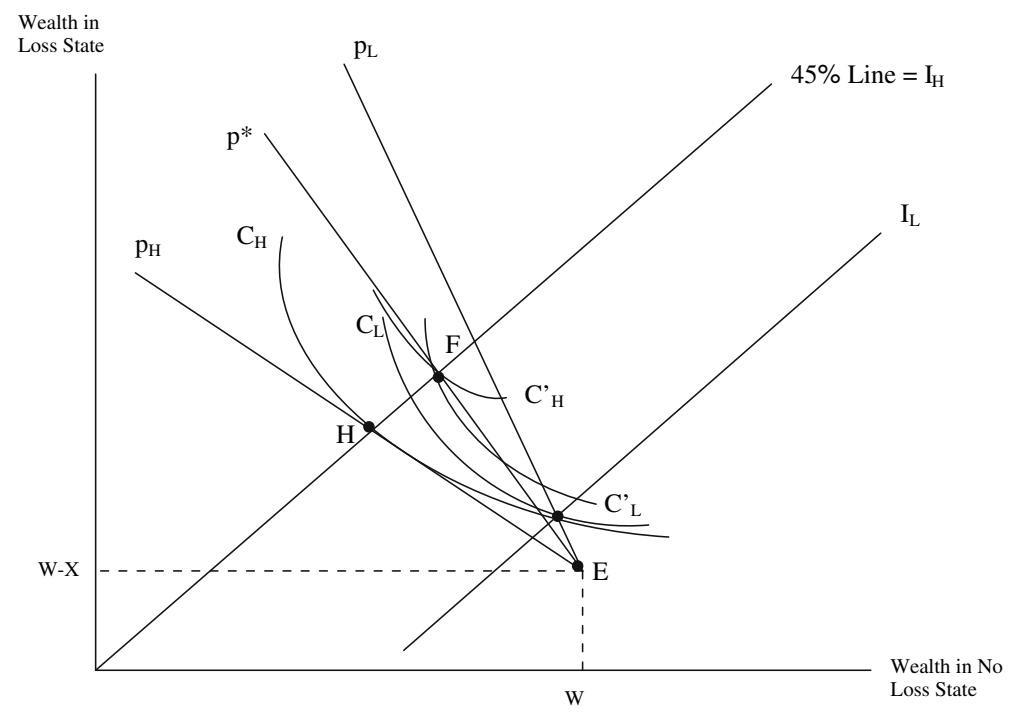

Fig. 2 Proportion of high risks too small for a separating equilibrium to exist

this case, no equilibrium exists for the following reason. Competition will drive the pooling contract to the zero-profit full insurance pooling contract $F$ in Fig. 2. But such a pooling equilibrium cannot be sustained in the R-S model because at that contract, the low risk indifference curve is steeper than the pooled price line while the high risk indifference curve is flatter. Therefore, a contract can be offered from the region between $C_{L}^{\prime}$ and the pooled price line which will attract only low risks away from the pooling contract $F$, making positive profits and causing $F$ to make negative profits. Therefore, the proportion $\lambda$ of high risks in the market (which determines $p^{*}$ ) is crucial to the question of whether the separating Nash equilibrium or any Nash equilibrium exists. If $\lambda$ is sufficiently small, then no equilibrium will exist.

In order to perform experiments to test for screening behavior by firms, we use a parameterized version of the R-S setup. It is assumed that consumers have exponential utility functions, $U(Y)=-e^{-r Y}$, with an Arrow-Pratt measure of absolute risk aversion $r=(\ln 4) / 3$ and a loss amount of $X=19.5$. The probabilities of loss for the two types are $p_{H}=1 / 5, p_{L}=1 / 15$. Note that with exponential utility functions, initial wealth has no impact on the outcome. Below we consider two cases with respect to the proportion of high risk individuals in the market, $\lambda=1 / 2$ and $\lambda=1 / 4$.

For $\lambda$ sufficiently large and with a continuum of price and quantity choices, the separating Nash equilibrium outcome for our parameterized version can be derived as follows. Since high risks obtain full insurance at their actuarially fair rate, their equilibrium contract is $\left(\alpha_{H}, I_{H}\right)=\left(p_{H} X, X\right)=(3.9,19.5)$. In deriving the low risk equilibrium contract, two things must be considered. First, the low risk contract is actuarially fair, so that $\left(\alpha_{L}, I_{L}\right)=\left(p_{L} I_{L}, I_{L}\right)=\left(1 / 5 I_{L}, I_{L}\right)$. Second, high risks are indifferent between the two contracts. Therefore, setting condition (3) as an 
equality, substituting $\alpha_{H}=3.9, I_{H}=19.5, p_{H}=1 / 5, p_{L}=1 / 15, X=19.5, U(Y)=-$ $e^{-r Y}, r=(\ln 4) / 3$ and $\alpha_{L}=1 / 5 I_{L}$, and solving for $I_{L}$ leads to a low risk equilibrium contract of $\left(\alpha_{L}, I_{L}\right)=(.9,13.5)$.

In order to make the experimental procedure tractable for subjects, the coverage options of the insurers are restricted to the two coverage levels, full and partial coverage, which are the separating equilibrium levels. These coverage restrictions are depicted in Figs. 1 and 2 as the lines $I_{H}$ and $I_{L} . I_{H}$ is the full insurance line; anywhere along this line, the policyholder's wealth is the same with or without a loss, and the price of the coverage determines where along this line a particular full insurance contract lies. The line $I_{L}$ is the partial coverage line, representing all contracts where the quantity is restricted to be at the level obtained under the low risk separating Nash outcome $L$. Again, the price determines where along this line the contract falls, with prices decreasing in a northeasterly direction.

Next, we consider the impact of these coverage restrictions on the Nash equilibrium outcome. As Fig. 1 indicates, when the proportion of high risks is sufficiently high that the pooled price line does not cross the indifference curve $C_{L}$, the separating Nash equilibrium outcome of R-S continues to be the unique equilibrium outcome. On the other hand, as depicted in Fig. 2, when the proportion of high risks is sufficiently low that the pooled price line crosses $C_{L}$, the coverage restrictions alter the equilibrium outcome. Under both our experimental model and the R-S model the separating outcome cannot be the equilibrium since it can be broken by a contract between $C_{L}$ and the pooled price line $p^{*}$. However, unlike R-S, the pooling contract $F$ in our setting can be sustained as an equilibrium outcome. The reason is that the contracts that prevent the pooling contract $F$ from being an equilibrium outcome in R-S, i.e., the contracts between $C_{L}^{\prime}$ and $p^{*}$, are no longer available in our experimental setting.

In the parameterized model with quantity constraints, the exponential utility function implies the additional amount a consumer of a given risk type is willing to pay for full coverage over partial coverage is fixed rather than varying as prices vary. This is due to constant absolute risk aversion. High risks are willing to pay up to 3 units more for full coverage over partial coverage since 3.9 and .9 are the equilibrium premiums levels for full and partial coverage, respectively, and these contracts are designed to leave high risks indifferent. Low risks are willing to pay up to 1.5 units more for full coverage over partial coverage. ${ }^{7}$ When $\lambda=1 / 2$, the outcome will be the separating equilibrium, $\left(\alpha_{H}, I_{H}\right)=(3.9,19.5)$ and $\left(\alpha_{L}, I_{L}\right)=(.9$, $13.5)$. The only contract which could potentially break the equilibrium, the full coverage pooling contract, would have a zero expected profit premium of $\left(\lambda p_{H}+\right.$ $\left.(1-\lambda) p_{L}\right) 19.5=(2 / 15) 19.5=2.6$. This would require an additional payment of 1.7 for low risks over the partial coverage premium of .9 , which is more than what they are willing to pay.

\footnotetext{
7 This can be determined by finding the amount, $\pi$, that low risks will pay for full insurance which will leave them indifferent to the low risk separating Nash equilibrium contract $(.9,13.5): U(W-\pi)=\left(1-p_{L}\right)$ $U(W-.9)+p_{L} U(W-.9-19.5+13.5)$ where $W$ is the initial wealth. Given the parameters of our model, this becomes $\mathrm{e}^{r \pi}=\left(1-p_{L}\right) \mathrm{e}^{r(.9)}+p_{L} \mathrm{e}^{r(6.9)}$, which implies $4^{(\pi-.9) / 3}=(14 / 15)+(1 / 15) 4^{6 / 3}\left(\right.$ since $\mathrm{e}^{r}=$ $\left.4^{1 / 3}\right)$, hence $\pi=2.4$. Therefore, a low risk will pay up to $2.4-.9=1.5$ more for full coverage over partial coverage.
} 
When $\lambda=1 / 4$, the Nash equilibrium with this restriction is a pooling equilibrium where both risk types purchase full coverage at the zero-profit pooling premium of $\left(\lambda p_{H}+(1-\lambda) p_{L}\right) 19.5=(1 / 10) 19.5=1.95$. Therefore, the Nash equilibrium consists of a single contract $(1.95,19.5)$. To see why this pooling equilibrium survives in our parameterized version, note that firms need to offer partial coverage at a premium of $1.95-1.5=.45$ in order to attract low risks away from the pooling contract. But this would yield negative profits since the zero profit premium for the partial coverage contract for low risks is .9. Also note that the separating outcome cannot be an equilibrium when $\lambda=1 / 4$ because the low risks would rather pay 1.95 for full coverage than .9 for partial coverage.

The purpose of our experiment is to test if sellers in this parameterized screening model would separate when $\lambda=2$ and pool when $\lambda=1 / 4$. In addition, the experiment will test whether sellers would offer the contracts at their equilibrium prices.

\section{The experimental design}

We conducted six experimental sessions. The first three sessions involved 60 simulated high cost and 60 simulated low cost buyers $(\lambda=1 / 2)$ with separating equilibrium as the predicted outcome. High (low) cost buyers correspond to high (low) risk policyholders in the R-S model. We will refer to these sessions as the separating treatment sessions. The last three sessions involved 30 simulated high cost and 90 simulated low cost buyers $(\lambda=1 / 4$ with pooling as the predicted outcome. These sessions will be referred to as the pooling treatment sessions.

All 6 sessions of our experiment were divided into 35 identical trading periods. Given the lengthy nature of our instructions, we designated the first 5 rounds as practice rounds to give the subjects a chance to fully understand the game. In the following 30 rounds, the subjects played the same game for cash.

Each session involved a different set of 18 sellers, who sat at visually isolated terminals. Each seller had two types of services to sell: Service A and Service B. In each round, a seller was matched with two other sellers in the room. Thus, there were 6 groups of sellers in each round. Each seller was matched randomly with two different sellers in each of the 35 rounds. The three sellers in each group competed with each other to sell to a set of buyers. The identities of the sellers, including their assigned identification numbers, were kept anonymous so as to prevent sellers from building reputations during the experiment. This procedure was employed in order to capture the one-shot nature of the theoretical model.

Each trading period consisted of the following steps. First, each seller chose which service, A or B or both, to offer and posted a unit price for these services. Service A represents full coverage (19.5) and Service B represents partial coverage (13.5) from the parameterized R-S model of the previous section. Then a buying sequence started, with buyers purchasing according to a myopic optimizing algorithm explained below. After all the decisions were made, each seller was informed of the sale price for each service, the number of units s/he sold of each service, which buyer type(s) purchased which of his/her service(s), and his/her 
earnings for the round. This feedback pertained to the group of three sellers to which the seller belonged.

A seller's point earnings from the sale of each unit equaled the sale price minus cost for that unit. Following the parameterized version of the R-S model, the cost of selling a unit of Service A to a High Cost buyer was set at 3.9 points (the probability of a loss times the coverage level, $1 / 5 \times 19.5)$ while the cost of selling a unit of Service A to a Low Cost buyer was set at 1.3 points $(1 / 15 \times 19.5)$. Similarly, the cost of selling a unit of Service B to a High Cost buyer was set at 2.7 points (1/ $5 \times 13.5)$ while the cost of selling a unit of Service B to a Low Cost buyer was set at 0.9 points $(1 / 15 \times 13.5)$.

Unlike the sellers' decisions, the buyers' decisions did not involve any strategic considerations. Given the purely mechanical nature of the buyers' decisions in our setup, and to better focus on the sellers' actions, we simplified the experiment by automating the buyers' choices. ${ }^{8}$ Sellers were informed that the computer would make the choices for the buyers according to the following rules:

(i) Each buyer will purchase at most one unit of either Service A or B. As a first rule, each buyer compares the prices of the three sellers for the two services and identifies the seller that offers the lowest price for Service A and the seller that offers the lowest price for Service B.

(ii) Then, the two buyer types use the following rules in their purchases:

High Cost Buyers: They will never pay more than 16 points for Service A and more than 13 points for Service B. They are willing to pay up to 3 points more for Service A than Service B. That is, if the lowest price for Service A does not exceed the lowest price for Service B by more than 3 points, they will purchase Service A (from the seller that offered the lowest price for Service A). Otherwise, they will purchase Service B from the seller that offered the lowest price for Service B, provided the price is less than 13 points.

Low Cost Buyers: They will never pay more than 13.7 points for Service A and more than 12.2 points for Service B. They are willing to pay up to 1.5 points more for Service A than Service B. That is, if the lowest price for Service A does not exceed the lowest price for Service B by more than 1.5 points, they will purchase Service A (from the seller that offered the lowest price for Service A). Otherwise, they will purchase Service B from the seller that offered the lowest price for Service $\mathrm{B}$, provided the price is less than 12.2 points.

A seller's earnings in a round were determined by how many units of Service A and B s/he sold and to which type of buyers in that round. As a result, each seller's earnings in a round depended on his/her price choices and the price choices of the two sellers that s/he was matched with in that round. If it turned out that there was a tie for the lowest price between two or all three sellers for a service that buyers of

\footnotetext{
${ }^{8}$ Buyer behavior is often simulated in posted-offer type experiments in order to focus on seller decisions. Examples include Alger (1987), Davis and Holt (1996), Davis and Williams (1991) and Kruse et al. (1994). Stiglitz and Weiss (1983) note that, as opposed to signaling models, in screening models "only firms are active players....[and] in the insurance market studied by Rothschild-Stiglitz (1976), it is plausible to think of individuals as passively choosing from a set of insurance policies." (Pg. 247)
} 
either type decided to buy, then these buyers were shared equally among the sellers that charged the lowest price.

For $\lambda=1 / 2$, the equilibrium prediction with a continuum of price choices is that both services would be offered at their zero-profit prices, Service A at 3.9 and Service B at 0.9. However, given the practical impossibility of allowing sellers an unlimited number of decimal places for their price choices, sellers were restricted to choose prices in increments of one decimal. As a by product of these discrete pricing options, and since sellers are indifferent between earning zero profits and not selling, price combinations of 4 for Service A and 1 for Service B, and 3.9 for Service A and 1 for Service B are also Nash equilibrium outcomes with high cost buyers purchasing A and low cost buyers purchasing B. ${ }^{9}$ To see this, consider the case where all three insurers charge 4 for Service A and 1 for Service B and, consequently, each insurer obtains 20 buyers of each type. This yields a profit of 0.1 from each high and each low cost buyer. If an insurer deviates and offers Service A (Service B) at 3.9 (0.9), it would attract all 60 high (low) cost buyers but make zero profits from each of them. A similar argument explains why no insurer would have an incentive to deviate and offer Service B at 0.9 when all insurers are charging 3.9 for Service A and 1 for Service B.

We next consider why none of these separating equilibria can be broken by a pooling contract. In order to break any of these three separating outcomes with a pooling contract where both types buy Service A, an insurer needs to offer Service A at no more than 1.5 above the current price for Service B to attract low cost buyers. This would yield a price for Service A of 2.5 if B is currently priced at 1, or 2.4 if $\mathrm{B}$ is currently priced at 0.9 . Since the zero profit pooling price is 2.6 , neither of these potential deviations would yield nonnegative profits. Finally, we need to show that a pooling contract cannot be an equilibrium when $\lambda=1 / 2$ and price choices are limited to a single decimal place. If a pooling contract is offered by all insurers, only prices of 2.6 and 2.7 would survive competition. In the case of 2.7, each insurer would earn profits of $4(=40 \times 0.1)$. An insurer could deviate and offer Service B at 1.1, attract all 60 low cost buyers and obtain profits of $12(=60 \times 0.2)$. Similarly, in the case of 2.6, each insurer would earn zero profits and could deviate and offer Service B at a price of 1 and earn profits of $6(=60 \times 0.1)$.

For $\lambda=1 / 4$, the equilibrium prediction for a continuum of pricing options is for Service A to be sold at 1.95 and Service B not to be sold at all. However, with prices restricted to a single decimal place, 1.95 is not available to sellers, making 2.0 the unique pooling equilibrium price for Service A. To see why no separating contract can break the pooling equilibrium with Service A sold at 2.0, note that an insurer must price Service B at 0.4 or less to attract low cost buyers away from the pooling contract. Since the cost of Service B for low cost buyers is 0.9, this would yield negative profits. Finally, we need to show that a separating outcome cannot be an equilibrium when $\lambda=1 / 4$ and price choices are limited to a single decimal place. If a separating equilibrium exists, competition would force it to be one of the following

\footnotetext{
$\overline{9}$ Note that price combination 4.0 and 0.9 is not a Nash equilibrium because the difference between the two exceeds 3 , in which case the high cost as well as low cost buyers would prefer the partial insurance contract.
} 
three price combinations for Service A and Service B, respectively: $(4,1),(3.9,1)$ and $(3.9, .9)$. Furthermore, recall that a pooling contract can break a potential separating equilibrium if Service A is offered at a price low enough to attract low cost buyers away from Service B. In this setting, this occurs when the price of Service A is no more than 1.5 above the current price of Service B. This means that a pooling contract with a price of 2.5 will be preferred by all buyers to either $(4,1)$ or $(3.9,1)$. Furthermore, a firm that offers such a pooling contract will earn profits of 66 $(=(2.5-1.95) \times 120)$ which exceed the profits from separating outcome $(4,1)$, $0.1 \times 40=4$, and the profits from separating outcome $(3,9,1), 0.1 \times 20=2$. Similarly, a pooling contract with a price of 2.4 for Service A will be preferred by all buyers to $(3.9, .9)$ and a firm that offers such a contract will earn profits of 54 $(=(2.4-1.95) \times 120)$ which exceeds the zero profits from the separating outcome $(3.9, .9)$.

\section{Experimental procedures ${ }^{10}$}

All six sessions were conducted in June 1998 at the Pennsylvania State University. Each treatment used 54 subjects, 18 in each of three sessions, who had signed up in response to fliers posted around campus. The fliers indicated that the average earnings for participants would be $\$ 23$ for a session lasting less than $2 \mathrm{~h}$. Each subject participated in one session only. Subjects were seated in front of computer terminals, read aloud a set of instructions and given an opportunity to ask questions. We then conducted the 5 practice rounds in which earnings were hypothetical, and at the end of each practice round we gave subjects another opportunity to ask questions. No communication between subjects was permitted during any of the sessions.

Given the nature of the game subjects played, it was very difficult for us to predict the point earnings for the subjects. A subject's potential earnings could be as high as 1420 points in the separating treatment sessions (selling $\mathrm{A}$ at 16 to high costs and $\mathrm{B}$ at 13 to low costs) while among the theoretical predictions was 0 points. Subjects could lose points as well if they priced below cost. Such extreme earnings predictions associated with each treatment made it difficult to assign a proper exchange rate for their point earnings. To make sure the average participant would earn a reasonable amount, we decided to calculate the exchange rate at the end of each session such that the average earnings in that session would be $\$ 20$ per subject. The instructions informed the participants that their point earnings from rounds 6 through 35 would be multiplied by an exchange rate of [ $\$ 20 /$ the average point earnings per participant]. It is important to note that this payoff structure does provide the subjects with monetary incentives to maximize their points earnings. The higher a subject's point earnings were, the greater his/her dollar earnings would be. In fact, there was considerable variation across subjects' earnings. They ranged from $\$ 3$ to $\$ 59.75$ in the separating sessions, and from $\$ 3$ to $\$ 101.75$ in the pooling

\footnotetext{
${ }^{10}$ Instructions are available from the authors upon request.
} 
sessions. We also paid each subject an additional $\$ 3$ for participating in the experiment. ${ }^{11}$ The sessions averaged 110 minutes.

Sellers chose prices by entering a number in increments of one decimal between 0 and 16 for Service A and between 0 and 13 for Service B. ${ }^{12}$ They were told that if they choose not to offer a particular service, then they could type " $x$ " rather than a price in the corresponding space. ${ }^{13}$ After all three sellers in each group posted their prices, the computer made the purchasing decisions for each type of buyer group according to the rules described earlier, and informed each seller of the sale price for each service, the number of units that the seller sold of each service to each buyer type, and his/her earnings for the round.

Note that sellers were permitted to choose prices below cost. It is also possible that a seller could offer a price for a service with the expectation that it would be purchased by only low cost buyers, but instead high cost buyers would purchase it and cause the seller to suffer a loss. Therefore, it was possible for a seller to have negative earnings in any round.

\section{Experimental results ${ }^{14}$}

The results of the separating treatment sessions, Sessions S1, S2 and S3, are summarized in Fig. 3. This figure displays the average posted price by sellers and the average transaction price for each service in each round of sessions $1-3$. Table 1 reports the frequency of the equilibrium play: the proportion of seller trios (markets) in which the transaction prices of the two services were an equilibrium combination (any of the three equilibrium price combinations).

In spite of the complicated nature of the experiment, our results from the separating sessions are quite clear. Although less than half of the transaction prices were equilibrium prices in the first 5 rounds, the prices converged to an equilibrium quickly. In the last ten rounds, all the transaction prices in each session were equilibrium prices, except for round 27 in session S1 and rounds 26 and 27 in session S3. In the last three rounds of each session, every transaction took place at equilibrium prices. ${ }^{15}$ Such a sharp outcome in a relatively complicated experiment illustrates the power of competition. Even if some sellers had been slow to

\footnotetext{
11 After calculating earnings according to the preceding formula, we did not require those subjects with negative earnings to pay us (i.e., they earned \$3). 19 out of 108 subjects would have had negative earnings but the money losing strategies were played in the early rounds of the sessions. Of the 1080 price pairings posted by the subjects in the last 10 rounds of our sessions, only 7 price pairings led to negative earnings.

12 Since no buyer is willing to pay more than 16 for Service A and more than 13 for Service B, the upper limit on prices does not affect the equilibrium predictions.

13 If a seller did not enter a price within $60 \mathrm{~s}$ of receiving the prompt, his/her prices for that round would be submitted as blank and s/he would not sell any units in that round (this did not occur in any of the sessions).

${ }^{14}$ We exclude the data from the practice round from all calculations in this section. A complete set of the data is available from either author upon request.

15 Almost all of the equilibrium transactions took place at a price of 4 for Service A and a price of 1 for Service B.
} 

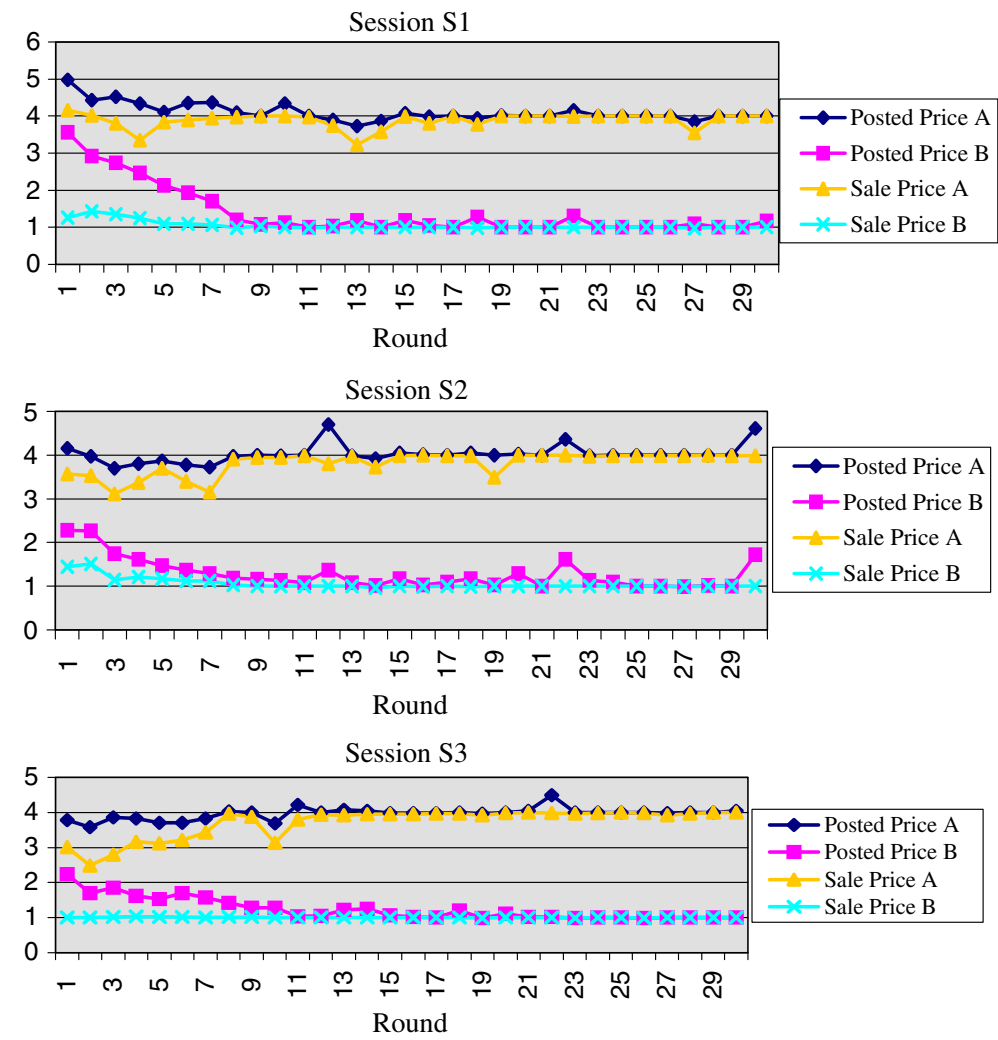

Fig. 3 Average posted price and average sale price for service A and B in separating treatment sessions

understand the game or resisted playing the equilibrium strategy initially, the feedback that they received about the selling prices at the end of each round made it clear to them that they had to change their prices or offerings in order to be able to make non-negative profits. ${ }^{16}$ As Fig. 3 illustrates, not only did the transaction prices converge, but the posted prices of each seller converged to the equilibrium prediction as well.

Figure 3 also indicates that the average sale price for Service A is below the separating equilibrium price in many of the early rounds. This would lead to negative expected profits for a firm if it were playing a separating strategy. But if it were playing a pooling strategy and expected the other firms to do the same, the prices observed in the early rounds would lead to positive expected profits. This indicates that some firms attempted to play a pooling strategy in the early rounds, but competition from other firms who were able to attract low cost customers to Service B left them with negative profits and an incentive both to increase the price of Service A and to move to a separating strategy.

\footnotetext{
${ }_{16}$ In fact, most of the variation in profits between the participants was due to differences in pricing strategies in the early rounds.
} 
Table 1 Proportion of markets with separating equilibrium in sessions $1-3(\lambda=1 / 2)$

\begin{tabular}{|c|c|c|c|}
\hline \multirow[t]{2}{*}{ Round } & \multicolumn{3}{|c|}{ Proportion of markets with separating equilibrium } \\
\hline & Session 1 & Session 2 & Session 3 \\
\hline 1 & 0 & 0 & 0.33 \\
\hline 2 & 0 & 0 & 0 \\
\hline 3 & 0.17 & 0 & 0.17 \\
\hline 4 & 0.17 & 0 & 0.17 \\
\hline 5 & 0.33 & 0.5 & 0.33 \\
\hline 6 & 0.5 & 0.17 & 0.17 \\
\hline 7 & 0.67 & 0.17 & 0.33 \\
\hline 8 & 0.83 & 0.33 & 0.83 \\
\hline 9 & 0.83 & 0.67 & 0.5 \\
\hline 10 & 1 & 1 & 0.5 \\
\hline 11 & 0.83 & 1 & 0.67 \\
\hline 12 & 0.83 & 0.83 & 0.83 \\
\hline 13 & 0.67 & 1 & 0.83 \\
\hline 14 & 0.67 & 0.67 & 1 \\
\hline 15 & 1 & 1 & 1 \\
\hline 16 & 0.83 & 0.83 & 1 \\
\hline 17 & 1 & 1 & 1 \\
\hline 18 & 0.67 & 0.83 & 1 \\
\hline 19 & 1 & 0.83 & 0.83 \\
\hline 20 & 1 & 1 & 1 \\
\hline 21 & 1 & 1 & 1 \\
\hline 22 & 1 & 1 & 1 \\
\hline 23 & 1 & 1 & 1 \\
\hline 24 & 1 & 1 & 1 \\
\hline 25 & 1 & 1 & 1 \\
\hline 26 & 1 & 1 & 0.83 \\
\hline 27 & 0.83 & 1 & 0.83 \\
\hline 28 & 1 & 1 & 1 \\
\hline 29 & 1 & 1 & 1 \\
\hline 30 & 1 & 1 & 1 \\
\hline
\end{tabular}

A comparison of the three separating treatment sessions indicates that there was not a statistically significant difference among the sessions, and thus among the player cohorts in these sessions. Table 2 presents t-tests for the following hypotheses: $\mathrm{H}_{01}: \mu_{\mathrm{s} 1}=\mu_{\mathrm{s} 2}, \mathrm{H}_{02}: \mu_{\mathrm{s} 2}=\mu_{\mathrm{s} 3}$ and $\mathrm{H}_{03}: \mu_{\mathrm{s} 1}=\mu_{\mathrm{s} 3}$ where $\mu_{\mathrm{si}}$ is the proportion of transaction prices in session $\mathrm{S}_{\mathrm{i}}, \mathrm{i}=1,2,3$, that are equilibrium prices. The statistics are based on the last 5 rounds, the last 15 rounds, and all 30 rounds. As the $p$-values in Table 2 indicate, there was no difference between any of the three separating treatment sessions at the $10 \%$ significance level.

Figure 4 summarizes the posted prices and selling prices in the pooling treatment sessions, P1, P2 and P3. A sale price of zero for a service in Fig. 4 represents the 
Table 2 Statistical tests for session effects for the separating treatment ${ }^{\mathrm{a}}$

\begin{tabular}{llll}
\hline Dependent Variable & Observations & $\begin{array}{l}\text { Proportion of equilibrium } \\
\text { outcomes }\end{array}$ & $p$-value $^{\mathrm{b}}$ \\
\hline Proportion of markets with Separating & $\mathbf{3 0}$ & $\mathbf{9 6 7}$ & \\
Equilibrium in Session S1 & $\mathbf{9 0}$ & $\mathbf{. 9 5 6}$ & \\
& 180 & .761 & \\
Proportion of markets with Separating & $\mathbf{3 0}$ & $\mathbf{1 . 0 0}$ & \\
Equilibrium in Session S2 & $\mathbf{9 0}$ & $\mathbf{. 9 6 7}$ & \\
& 180 & .728 & \\
Proportion of markets with Separating & $\mathbf{3 0}$ & $\mathbf{. 9 3 3}$ & $\mathbf{3 1 7}$ \\
Equilibrium in Session S3 & $\mathbf{9 0}$ & $\mathbf{. 9 6 7}$ & $\mathbf{. 7 0 4}$ \\
& 180 & .739 & .472 \\
Difference in Proportions & & & $\mathbf{. 5 4 9}$ \\
(Session S1 - Session S2) & & & .704 \\
& & & .631 \\
Difference in proportions & & & $\mathbf{. 1 5 0}$ \\
(Session S1 - Session S3) & & & $\mathbf{1 . 0 0}$ \\
& & & .816 \\
\hline Difference in proportions & &
\end{tabular}

\section{Using data from last 5 rounds}

Using data from last 15 rounds

using data from all rounds

${ }^{a}$ These are $t$-tests with the null hypothesis that the Proportion of equilibrium prices is the same in both sessions

b The reported $p$-values reflect the probability of a deviation from zero more extreme than the observed deviation, when the null hypothesis is true

case where no buyers purchased that service. The equilibrium prediction is for Service A to be sold at 2 and Service B not to be offered at all. We anticipated that obtaining the equilibrium outcome in the pooling treatment sessions would be more complicated than the separating treatment sessions; in the separating treatment sessions the competition among the sellers forced them to price each service at its cost where the only critical question was whether they would be selling each service to the buyer type to which they intended to sell. The pooling equilibrium, on the other hand, requires at least one seller to realize that if all sellers offered both of the services, then s/he could profit from offering Service A only at such a price that would attract all buyers of both types. However, s/he also must realize that if s/he offers Service A only and prices it with the expectation that all buyer types would buy it, s/he runs the risk that some other seller's price for Service B may attract all the low cost buyers, and as a result s/he may end up selling to high cost buyers only and incurring a loss. 

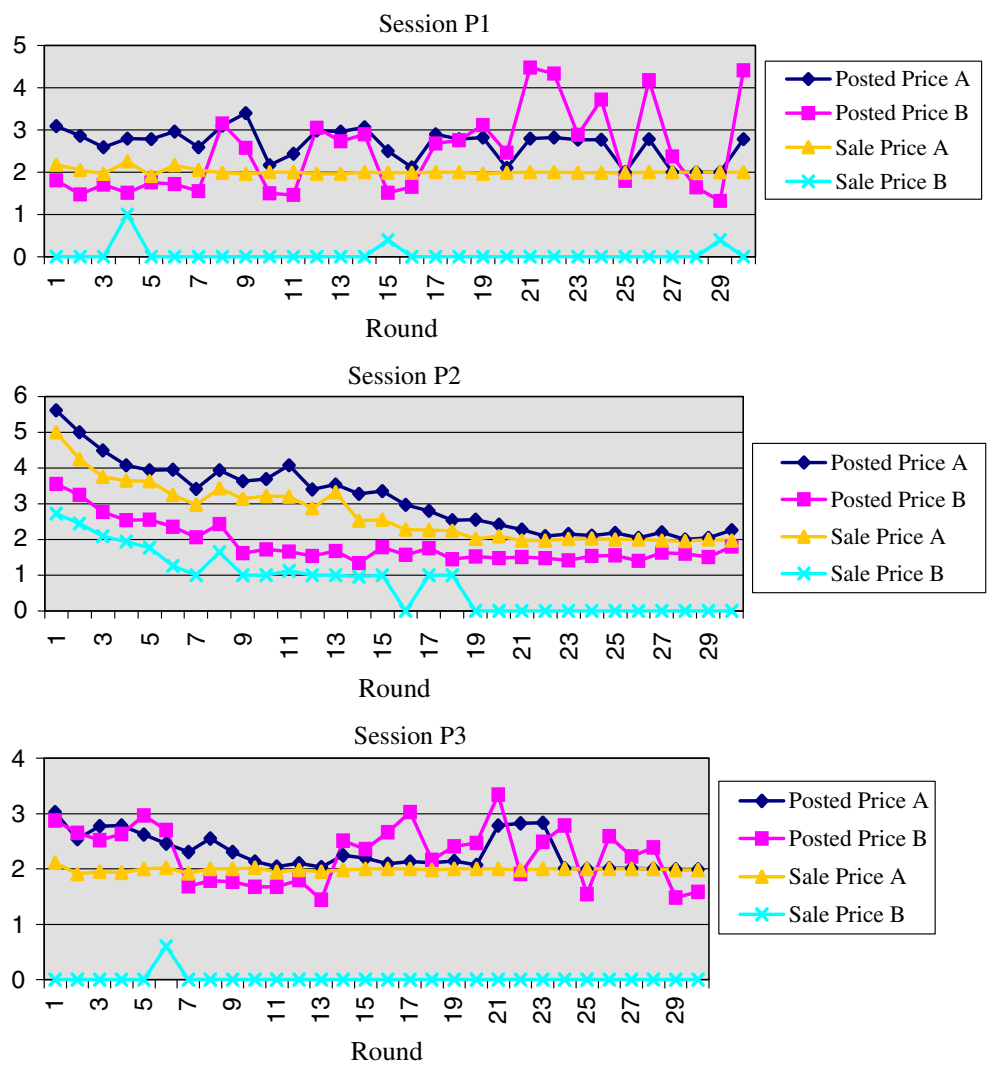

Fig. 4 Average posted price and average sale price for service A and B in pooling treatment sessions

The more complicated nature of the pooling sessions can be seen in the posted prices in Fig. 4. Since the average price for B is calculated using only prices at which B was offered (i.e., not including " $\mathrm{x}$ " choices by sellers) the average posted prices for $B$ on the figure capture only those which are not " $\mathrm{x}$ " choices (recall that if all prices in a round are " $\mathrm{x}$ ", then the average price in the figures appears as zero for that round). Note that not all the posted prices converged to the equilibrium. ${ }^{17}$ However, a great majority of transactions were in line with the equilibrium prediction. As displayed in Table 3, in 6 of the last 10 rounds of Session P1 and in 7 of the last 10 rounds of Session P3, all the Service A units were sold at the equilibrium price of 2 and Service B was not sold at all. The results of Session P2 were weaker; in only 3 of the last 10 rounds, the observed behavior was entirely in line with the equilibrium prediction.

\footnotetext{
17 It should be pointed out that $87 \%$ of posted price pairs in the last 5 rounds of the pooling sessions were equilibrium prices. If a seller offers Service B at a high enough price at which no buyer type would buy it (e.g., if the difference between his/her price for Service A and Service B is less than 1.5 or if his/her price for B exceeds 13.7), then this would effectively mean that s/he did not want to sell Service B. Therefore, we include prices of 2 for $\mathrm{A}$ and $>.5$ for $\mathrm{B}$ as equilibrium posted prices.
} 
Table 3 Proportion of markets with pooling outcomes and proportion of markets with pooling equilibrium outcomes in sessions $4-6(\lambda=1 / 4)$

\begin{tabular}{|c|c|c|c|c|c|c|}
\hline \multirow[t]{2}{*}{ Round } & \multicolumn{3}{|c|}{$\begin{array}{l}\text { Proportion of markets with pooling } \\
\text { outcomes }\end{array}$} & \multicolumn{3}{|c|}{$\begin{array}{l}\text { Proportion of markets with pooling equilibrium } \\
\text { outcomes }\end{array}$} \\
\hline & Session 4 & Session 5 & Session 6 & Session 4 & Session 5 & Session 6 \\
\hline 1 & 1 & 0 & 1 & 0.17 & 0 & 0.17 \\
\hline 2 & 1 & 0.33 & 1 & 0.17 & 0.17 & 0.33 \\
\hline 3 & 1 & 0.33 & 1 & 0.67 & 0 & 0.17 \\
\hline 4 & 0.83 & 0.5 & 1 & 0.17 & 0 & 0.5 \\
\hline 5 & 1 & 0.33 & 1 & 0.5 & 0 & 0.5 \\
\hline 6 & 1 & 0.5 & 0.83 & 0.83 & 0.17 & 0.5 \\
\hline 7 & 1 & 0.67 & 1 & 0.5 & 0.17 & 0.33 \\
\hline 8 & 1 & 0.17 & 1 & 0.67 & 0 & 1 \\
\hline 9 & 1 & 0.17 & 1 & 0.5 & 0 & 1 \\
\hline 10 & 1 & 0.33 & 1 & 1 & 0.17 & 0.83 \\
\hline 11 & 1 & 0.33 & 1 & 1 & 0.17 & 0.5 \\
\hline 12 & 1 & 0.67 & 1 & 0.67 & 0 & 0.83 \\
\hline 13 & 1 & 0.33 & 1 & 0.83 & 0.17 & 0.5 \\
\hline 14 & 1 & 0.67 & 1 & 1 & 0 & 0.83 \\
\hline 15 & 0.83 & 0.83 & 1 & 0.67 & 0 & 1 \\
\hline 16 & 1 & 1 & 1 & 0.83 & 0 & 1 \\
\hline 17 & 1 & 0.83 & 1 & 1 & 0.17 & 1 \\
\hline 18 & 1 & 0.83 & 1 & 1 & 0.17 & 0.83 \\
\hline 19 & 1 & 1 & 1 & 0.83 & 0.33 & 1 \\
\hline 20 & 1 & 1 & 1 & 0.83 & 0.33 & 1 \\
\hline 21 & 1 & 1 & 1 & 1 & 0.5 & 1 \\
\hline 22 & 1 & 1 & 1 & 1 & 0.33 & 0.83 \\
\hline 23 & 1 & 1 & 1 & 0.83 & 0.67 & 1 \\
\hline 24 & 1 & 1 & 1 & 0.83 & 0.83 & 1 \\
\hline 25 & 1 & 1 & 1 & 0.83 & 1 & 1 \\
\hline 26 & 1 & 1 & 1 & 1 & 1 & 1 \\
\hline 27 & 1 & 1 & 1 & 1 & 0.67 & 1 \\
\hline 28 & 1 & 1 & 1 & 1 & 0.67 & 1 \\
\hline 29 & 0.83 & 1 & 1 & 0.83 & 1 & 0.83 \\
\hline 30 & 1 & 1 & 1 & 1 & 0.67 & 0.83 \\
\hline
\end{tabular}

It is important to note that the divergence of some of the transactions from the equilibrium prediction in the pooling sessions were mostly with respect to the price of Service A, not with respect to "pooling." As Table 3 shows, with the exception of a single round in Session P1, each transaction in each of the last 10 rounds of every session involved a pooling outcome where only Service A was sold. The discrepancy between the two columns of Table 3, "Proportion Of Markets With Pooling Outcomes" and "Proportion Of Markets With Pooling Equilibrium 
Outcomes," is due to the fact that a few of the selling prices for Service A were different than 2 . The typical deviation was to the price of 1.9 , which indicates an attempt by some sellers to capture the whole market, albeit at a loss.

We attribute the high percentage of pooling equilibrium outcomes in sessions P1$\mathrm{P} 3$, in spite of the complicated nature of the game, again to the power of competition. It is not trivial for subjects to figure out that offering Service A only at a certain price will gain him/her the whole market. However, all it takes for a market to realize this is for one seller in that market to discover this opportunity. Once a seller in a market steals all the buyers by offering a pooling contract, the other sellers realize that they will have to offer a similar contract. Eventually, all sellers start offering the equilibrium contract.

There was a session effect between Session P2 and the sessions P1 and P3. As reported in Table 4, Session P2 was significantly different than Session P1 in the last 5, last 15, and all rounds, and it was significantly different than Session P3 in the

Table 4 Statistical tests for session effects for the pooling treatment ${ }^{\mathrm{a}}$

\begin{tabular}{|c|c|c|c|}
\hline Dependent variable & Observations & $\begin{array}{l}\text { Proportion of equilibrium } \\
\text { outcomes }\end{array}$ & $p$-value ${ }^{\mathrm{b}}$ \\
\hline \multirow{3}{*}{$\begin{array}{l}\text { Proportion of markets with Pooling } \\
\text { Equilibrium in Session P1 }\end{array}$} & 30 & .967 & \\
\hline & 90 & .922 & \\
\hline & 180 & .778 & \\
\hline \multirow{3}{*}{$\begin{array}{l}\text { Proportion of markets with Pooling } \\
\text { Equilibrium in Session P2 }\end{array}$} & 30 & .800 & \\
\hline & 90 & .556 & \\
\hline & 180 & .311 & \\
\hline \multirow{3}{*}{$\begin{array}{l}\text { Proportion of markets with Pooling } \\
\text { Equilibrium in Session P3 }\end{array}$} & 30 & .933 & \\
\hline & 90 & .956 & \\
\hline & 180 & .778 & \\
\hline \multirow{3}{*}{$\begin{array}{l}\text { Difference in proportions } \\
\quad(\text { Session P1 - Session P2) }\end{array}$} & & & .044 \\
\hline & & & .000 \\
\hline & & & .000 \\
\hline \multirow{3}{*}{$\begin{array}{l}\text { Difference in proportions } \\
\quad(\text { Session P1 - Session P3) }\end{array}$} & & & .548 \\
\hline & & & .342 \\
\hline & & & 1.00 \\
\hline \multirow{3}{*}{$\begin{array}{l}\text { Difference in proportions } \\
\quad(\text { Session P2 - Session P3) }\end{array}$} & & & .130 \\
\hline & & & .000 \\
\hline & & & .000 \\
\hline
\end{tabular}

\section{Using data from last 5 rounds}

\section{Using data from last 15 rounds}

Using data from all rounds

${ }^{a}$ These are $t$-tests with the null hypothesis that the Proportion of equilibrium prices is the same in both sessions

b The reported $p$-values reflect the probability of a deviation from zero more extreme than the observed deviation, when the null hypothesis is true 
last 15 rounds and in all rounds. Session P1 and P3 did not exhibit significant differences.

Our last test deals with the main objective of the experiment: would a change in the proportion of high cost and low cost buyers induce a change in the pricing strategies of the sellers? The instructions we used for the separating and pooling sessions were identical except for the line where we changed the number of high cost buyers from 60 to 30 and the number of low cost buyers from 60 to 90 . Table 5 confirms what has already become clear from Figs. 1 and 2; there was a significant change in the proportion of times the observed prices were a separating equilibrium outcome as we changed the proportion of high cost buyers from 2 to 3 . The proportion of separating equilibrium outcomes in the last 15 rounds dropped from near 1 in sessions $\mathrm{S} 1, \mathrm{~S} 2$ and $\mathrm{S} 3$ to near 0 in sessions P1, P2 and P3.

\section{Conclusion}

In this paper, we conduct an experimental test of a parameterized version of the Rothschild-Stiglitz screening model. Our focus is on the strategic behavior of firms with the option to offer menus of contracts to screen buyers by risk type. Our results provide striking evidence of screening behavior by sellers. In the first three sessions of our experiment the proportion of high risk buyers is such that a separating Nash equilibrium exists. In each of these sessions, almost all of the markets have the separating equilibrium in the last 10 rounds. Sellers in our experiment screen high risk and low risk buyers as well as price both the full coverage and partial coverage contracts at their equilibrium levels. In the three remaining sessions the proportion of high risks is increased sufficiently such that the equilibrium is a pooling equilibrium with only the full coverage contract being offered. Again, the observed

Table 5 A comparison of the separating and pooling sessions ${ }^{\mathrm{a}}$

\begin{tabular}{lllll}
\hline Round(s) & $\begin{array}{l}\text { Observations } \\
\text { Per Treatment }\end{array}$ & $\begin{array}{l}\text { Number (proportion) } \\
\text { of separating equilibrium } \\
\text { outcomes in P1 + P2 + P3 }\end{array}$ & $\begin{array}{l}\text { Number (proportion) of } \\
\text { separating equilibrium } \\
\text { outcomes S1 + S2 + S3 }\end{array}$ & $p$-value \\
\hline $1-5$ & 90 & $1(.01)$ & $13(.14)$ & 0 \\
$6-10$ & 90 & $6(.07)$ & $51(.57)$ & 0 \\
$11-15$ & 90 & $8(.09)$ & $77(.86)$ & 0 \\
$16-20$ & 90 & $0(0.0)$ & $83(.92)$ & 0 \\
$21-25$ & 90 & $0(0.0)$ & $90(1.0)$ & 0 \\
$26-30$ & 90 & $0(0.0)$ & $87(.97)$ & 0 \\
$16-30$ & 270 & $0(0.0)$ & $260(.96)$ & 0 \\
$1-30$ & 540 & $15(.03)$ & $401(.74)$ & 0 \\
30 & 18 & $0(0.0)$ & $18(1.0)$ & 0
\end{tabular}

\footnotetext{
a These are $t$-tests with the null hypothesis that the Proportion of separating equilibrium prices is the same in sessions $\mathrm{S} 1+\mathrm{S} 2+\mathrm{S} 3$ and $\mathrm{P} 1+\mathrm{P} 2+\mathrm{P} 3$

$\mathrm{b}$ The reported $p$-values reflect the probability of a deviation from zero more extreme than the observed deviation, when the null hypothesis is true
} 
behavior converges to the equilibrium prediction, although at a slower rate than it did in the three separating equilibrium sessions.

We attribute these results to the competitive structure of our experimental design. Attempts by some sellers to play non-equilibrium strategies in early rounds ultimately yielded either negative profits or a lack of customers. Competition not only drove prices to their competitive levels, but also induced firms to play the equilibrium strategy of separating or pooling.

Our results provide strong support for screening behavior by sellers in an asymmetric information environment. Although stylized laboratory markets do not necessarily reflect what happens in richer natural contexts, the strength of our results indicate that natural environments may exist where the R-S model can predict behavior.

In our experiment, the sellers choose which of the two coverage levels to offer and at what prices. An alternative experiment for future research would involve allowing sellers to choose from a large set of coverage levels as well as price levels. Given that this is likely to result in a wide range of coverage and price offerings by firms, the buyer's problem may be less trivial. Hence, it would also be useful to replace automated buyers with subjects who play the role of buyers. This would require sellers to make conjectures about the behavior of buyers as well as the behavior of other sellers. This would also allow for the possibility that social considerations such as fairness and reciprocity would influence players' decisions. Another extension would include altering the information feedback in the experiment to give an opportunity for the emergence of coalition strategies. An additional possible extension would be to alter the incentive scheme such that subjects' compensation would depend on their absolute point earnings, rather than on relative point earnings. Although such an alteration of the incentive scheme would not alter the theoretical predictions, it may have an impact on observed behavior.

Acknowledgements We thank Martin Sefton, Mark Walker, Stanley Reynolds, Stephane Aymard, John Dickhaut, participants at the 1999 Economic Science Association, 1999 Risk Theory Seminar, the 9th Annual Conference on the Foundations of Uncertainty and Risk, Marrakesh, Morocco, and XII World Congress of the International Economic Association, Buenos Aires, Argentina.

\section{References}

Alger D (1987) Laboratory Tests of equilibrium predictions with disequilibrium data. Rev Econ Stud 54:105-145

Browne MJ (1992) Evidence of adverse selection in the individual health insurance market. J Risk Insurance 59:13-33

Browne MJ, Doerpinghaus HI (1994) Asymmetric information and the demand for medigap insurance. Inquiry 31:445-450

Brueckner JK (1992) Mobility, Self-selection and the relative prices of fixed- and adjustable rate mortgages. J Financ Intermediat 2:401-421

Cadsby CB, Frank M, Maksimovic V (1990) Pooling, separating and semiseparating equilibria in financial markets: some experimental evidence. Rev Financ Stud 3:315-342

Cooper R, Hayes B (1987) Multi-period insurance contracts. Int J Indust Org 5:211-231 
Crocker KJ, Snow A (1985) The efficiency of competitive equilibria in insurance markets with asymmetric information. J Publ Econ 26:207-219

Crocker KJ, Snow A (1986) The efficiency of categorical discrimination in the insurance industry. J Politic Econ 94:321-344

Dahlby BG (1983) Adverse selection and statistical discrimination. J Publ Econ 20:121-130

D' Arcy S, Doherty NA (1990) Adverse selection, private information, and lowballing in insurance markets. J Bus 63:145-164

Davis DD, Holt CA (1996) List prices and discounts: the interrelationship between consumer shopping patterns and profitable marketing strategies. Psychol Market 13:341-363

Davis DD, Williams AW (1991) The Hayek hypothesis in experimental auctions: institutional effects and market power. Econ Inq 29:261-274

Doherty NA, Posey LL (1998) On the value of a checkup: moral hazard, adverse selection and the value of information. J Risk Insurance 65:189-211

Hoy M (1982) Categorizing risks in the insurance industry. Quart J Econ 97:321-336

Kruse JB, Rassenti S, Reynolds SS, Smith VL (1994) Bertrand-Edgeworth competition in experimental markets. Econometrica 62:343-372

Kübler D, Müller W, Normann H-T (2005) Job market signaling and screening: An experimental comparison, IZA Bonn Discussion Paper 1794

Miller RM, Plott CR (1985) Product quality signaling in experimental markets. Econometrica 53:837-871

Puelz R, Snow A (1994) Evidence on adverse selection: equilibrium signaling and cross-subsidization in the insurance market. J Politic Econ 102:236-57

Riley JG (1979) Informational Equilibria. Econometrica 47:331-359

Rothschild M, Stiglitz JE (1976) Equilibrium in competitive insurance markets: an essay on the economics of imperfect information. Quart J Econ 90:629-649

Rubinfeld DL, Schotchmer S (1993) Contingent fees for attorneys-an economic analysis. Rand J Econ 24:455-465

Shapira Z, Venezia I (1999) Experimental tests of self-selection and screening in insurance decisions. Geneva Pap Risk Insur Theory 24:139-158

Stiglitz J, Weiss A (1981) Credit rationing in markets with imperfect information. Am Econ Rev 71:393410

Stiglitz J, Weiss A (1983) Alternative approaches to analyzing markets with asymmetric information: reply. Am Econ Rev 73:246-249

Wilson C (1977) A model of insurance markets with incomplete information. J Econ Theory 12:167-207 